\title{
Warburg effect hypothesis in autism Spectrum disorders
}

\author{
Alexandre Vallée ${ }^{1,2^{*}}$ and Jean-Noël Vallée ${ }^{2,3}$
}

\begin{abstract}
Autism spectrum disorder (ASD) is a neurodevelopmental disease which is characterized by a deficit in social interactions and communication with repetitive and restrictive behavior. In altered cells, metabolic enzymes are

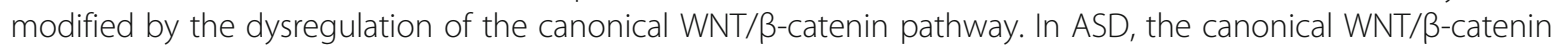
pathway is upregulated. We focus this review on the hypothesis of Warburg effect stimulated by the overexpression of the canonical WNT/ $\beta$-catenin pathway in ASD. Upregulation of WNT/ $\beta$-catenin pathway induces aerobic glycolysis, named Warburg effect, through activation of glucose transporter (Glut), pyruvate kinase M2 (PKM2), pyruvate dehydrogenase kinase 1(PDK1), monocarboxylate lactate transporter 1 (MCT-1), lactate dehydrogenase kinase-A (LDH-A) and inactivation of pyruvate dehydrogenase complex (PDH). The aerobic glycolysis consists to a supply of a large part of glucose into lactate regardless of oxygen. Aerobic glycolysis is less efficient in terms of ATP production than oxidative phosphorylation because of the shunt of the TCA cycle. Dysregulation of energetic metabolism might promote cell deregulation and progression of ASD. Warburg effect regulation could be an attractive target for developing therapeutic interventions in ASD.
\end{abstract}

Keywords: WNT/ß-catenin pathway, Aerobic glycolysis, Warburg effect, Lactate, Autism spectrum disorders, LDH-a

\section{Background}

Autism spectrum disorders (ASD) is a neurodevelopmental disease which is characterized by a deficit in social interactions and communication with repetitive and restrictive behaviors [1], poor eye contact [2] and disruption of cognitive and motor development [3]. ASD is mainly diagnosed within the first three years of life. Early diagnosis is critical for better prognosis and therapeutic care $[4,5] .10 \%$ of ASD cases are associated with a "genetic syndromic ASD" and the other cases, as "idiopathic ASD" and "primary ASD", have no clearly known causes. Several genetic factor and environmental effects may contribute to the heterogeneity etiologic of this disease [6]. However, the etiology of ASD remains unknown.

Dysregulation of the core neurodevelopmental pathways is associated with the clinical presentation of ASD, and one of the major pathways involved in developmental

\footnotetext{
* Correspondence: alexandre.g.vallee@gmail.com

${ }^{1}$ Laboratoire de Mathématiques et Applications (LMA), UMR CNRS 7348, CHU

Poitiers, University of Poitiers, Poitiers, France

'Laboratoire de Mathématiques et Applications (LMA), UMR CNRS 7348,

University of Poitiers, 11 Boulevard Marie et Pierre Curie, Poitiers, France

Full list of author information is available at the end of the article
}

cognitive disorders is the canonical $\mathrm{WNT} / \beta$-catenin pathway [7]. Several genetic mutations observed in ASD are linked with the deregulation of the canonical WNT/ $\beta$-catenin pathway by interactions between chromodomain helicase DNA binding protein 8 (CDH8) and CTNNB1 ( $\beta$-catenin) [8]. Canonical $\mathrm{WNT} / \beta$-catenin pathway has a critical role in the development of the central nervous system (CNS), and is over-expressed in ASD $[7,9,10]$.

Metabolic enzymes are modified by the dysregulation of the canonical WNT/ $\beta$-catenin pathway. Upregulation of $W N T / \beta$-catenin signaling leads to activation of pyruvate dehydrogenase kinase-1 (PDK-1), which decreases the activity of the pyruvate dehydrogenase complex $(\mathrm{PDH})$. Upregulation of $\mathrm{WNT} / \beta$-catenin signaling also activates monocarboxylate lactate transporter-1 (MCT-1) [11]. This do not allow the conversion of pyruvate into acetyl-coenzyme A (acetyl-CoA) in mitochondria and its entry into the tricarboxylic acid (TCA) cycle. At this stage, cytosolic pyruvate is converted into lactate for the major party. This phenomenon is called Warburg effect or aerobic glycolysis despite the availability of oxygen [12]. 
Mitochondrial deregulation is one of the main metabolic abnormalities observed in ASD physiopathology [13-17]. Several studies have shown a significant increase in lactate dehydrogenase kinase A (LDH-A) expression and pyruvate levels [18] with an increased lactate/pyruvate ratio [19], and elevated levels of lactate in ASD patients [20, 21].

There is some common denominator between these metabolic abnormalities, which strongly suggests the reprogramming of cellular energy metabolism with increase lactate production induced by over-expressed canonical WNT/ $\beta$-catenin pathway in ASD.

We focus this review on the hypothesis of Warburg effect induced by over-expressed canonical WNT/ $\beta$-catenin pathway in ASD.

\section{Canonical WNT/ $\beta$-catenin pathway}

Wingless and integration site (called WNT) pathway is a cascade of several signaling implicated in development, growth, and metabolism [22]. WNT signaling is composed by secreted lipid-modified glycoproteins [23]. WNT/ $\beta$-catenin pathway is involved in numerous mechanisms such as patterning, development of synapses in the CNS [24, 25], synaptogenesis [26, 27] and the control of synaptic formation [24, 28].

Dysregulation of the canonical $\mathrm{WNT} / \beta$-catenin pathway is observed in numerous diseases [29], such as cancers, as gliomas [30, 31] and colon cancer [32], and neurodegenerative diseases as Alzheimer's disease $[33,34]$, age macular degeneration $[35,36]$, amyotrophic lateral sclerosis [37] and multiple sclerosis [38] (Table 1).

WNT family genes are 19 members which are classified as canonical and non-canonical WNT pathway. Canonical WNT ligands are seven, as WNT1, WNT2, WNT3, WNT8a, WNT8b, WNT10a and WNT10b). They are activators of the $\mathrm{WNT} / \beta$-catenin pathway. Canonical WNT ligands are secreted by neurons and immune cells in the CNS [39]. The non-canonical WNT pathway is independent to $\beta$-catenin signaling and is separated into the planar cell planar cell polarity pathway and the $\mathrm{WNT} / \mathrm{Ca}^{2+}$ pathway.

WNT extracellular ligands bind low density lipoprotein receptor-related protein 5 and 6 (LRP 5/6), Frizzled (FZD) receptors, and then disheveled (DSH), resulting in $\beta$-catenin accumulation and nuclear translocation. Thus, $\mathrm{N}$-nuclear $\beta$-catenin bind T-cell factor/lymphoid enhancer factor (TCF/LEF) [40]. The complex formed TCF/ LEF-nuclear $\beta$-catenin leads to the stimulation and the transcription of several WNT target genes (c-Myc, cyclin D1) [41].

The absence of binding between membrane receptors and WNT extracellular ligands characterizes the downregulation of $\mathrm{WNT} / \beta$-catenin pathway. The $\beta$-catenin complex destruction is formed by adenomatous polyposis
Table 1 Canonical WNT/ $\beta$-catenin pathway dysregulation

\begin{tabular}{lll}
\hline WNT/B-catenin & Pathologies & References \\
pathway & & \\
\hline Increase & Age-macular degeneration & {$[35,36]$} \\
& Aging & {$[113]$} \\
& Amyotrophic lateral sclerosis & {$[37]$} \\
& Atherosclerosis & {$[114]$} \\
& Cancers & {$[97]$} \\
Colon cancer & {$[115]$} \\
& Diabetes 2 & {$[32]$} \\
& Fibrosis & {$[116,117]$} \\
& Gliomas & {$[30,31]$} \\
& Huntington's disease & {$[118]$} \\
& Multiple sclerosis & {$[34]$} \\
& Radiation-induced fibrosis & {$[119]$} \\
& Alzheimer's disease & {$[33,34,120]$} \\
Arrhythmogenic right ventricular & {$[121]$} \\
cardiomyopathy & {$[122]$} \\
Becrease & Bipolar disorder & {$[123]$} \\
& Osteoporosis & {$[124]$} \\
Parkinson's disease &
\end{tabular}

coli (APC), AXIN and glycogen synthase kinase-3 $\beta$ (GSK-3 $\beta$ ). This complex binds $\beta$-catenin to degrade it into the proteasome [42]. Activated GSK-3 $\beta$ downregulates $\beta$-catenin accumulation and its nuclear translocation $[42,43]$.

\section{WNT/B-catenin pathway and PI3K/Akt pathway}

Phosphatidylinositol 3-kinase/serine/threonine kinase (protein kinase B)/mammalian target of rapamycin (PI3K/ Akt/mTOR) pathway is implicated in proliferation, growth, protein synthesis and metabolism [44-47]. WNT/ $\beta$-catenin pathway, through the inhibition GSK-3 $\beta$ activity [48], is considered as one of the main activator of PI3K/ Akt/mTOR pathway [49]. GSK-3 $\beta$, a major inhibitor of the WNT ligands [50], is a specific intracellular serine-threonine kinase which regulates numerous pathophysiological pathways [51-53]. PI3K/Akt pathway decreases the activity of GSK-3 $\beta$ in adipocyte differentiation $[54,55]$. In addition, decrease of $\beta$ catenin levels downregulates the expression of PI3K/ Akt/mTOR pathway [56, 57].

\section{Canonical WNT/ $\beta$-catenin and PI3K/Akt pathways in ASD}

Several studies have shown the major role of activated WNT/ $\beta$-catenin pathway in ASD [58-60]. Numerous genetic components are correlated with ASD development such as WNT2 ligand [61], hepatocyte growth factor receptor (MET) which is a WNT target gene 
$[62,63]$, and chromo-helicase domain protein 8 (CHD8) and DYRK1A which can both modulate WNT/ $\beta$-catenin pathway [64-66].

Several studies has shown a main role of numerous compounds of the $\mathrm{WNT} / \beta$-catenin pathway in ASD, such as WNT1 [67], WNT2 [61], WNT3 [68], WNT7A [69], APC [70-72], $\beta$-catenin $[8,73]$, TCF4 $[74,75]$ and TCF7 [76].

The knockout of the gene encoding phosphatase and tensin homolog protein (PTEN), a cytoplasmic protein suppressor of $\mathrm{WNT} / \beta$-catenin pathway, has been identified as a high-risk ASD susceptibility gene [77-80]. PTEN is also a negative regulator of PI3K/ Akt pathway [81] and deletion of PTEN expression leads to stimulate proliferation and migration through the activation of mTOR activity [82]. Knockout of PTEN in Purkinje cells impairs social relation, behavior and deficits in motor learning [83, 84]. PTEN and $\beta$-catenin regulate each other leading to normal growth of the brain [85].

\section{Valproate and ASD}

Valproate (or Valproic acid, VPA) is an anti-convulsing agent discovered in 1963 and used for treatment of bipolar disorders or migraine [86, 87]. VPA decreases GSK-3 $\beta$ activity and then stimulates $\mathrm{WNT} / \beta$-catenin pathway [88-90].

In neural stem cells of the CNS, VPA can increase WNT3a expression and $\beta$-catenin accumulation [90]. In rat models, treatment with VPA activates $\mathrm{WNT} / \beta$-catenin pathway and inhibits GSK-3 $\beta$ activity, which stimulates PI3K/Akt/mTOR pathway [89, 91]. VPA increases the risk of ASD in pregnant woman during prenatal development through the stimulation of $\mathrm{WNT} / \beta$-catenin pathway [92].

\section{Warburg effect}

The Warburg effect (also named aerobic glycolysis) consists to a conversion of a large part of glucose into lactate regardless of oxygen [12]. Activated PDK1 phosphorylates the PDH in order to stop the conversion of pyruvate into acetyl-coA in mitochondria [93]. This conversion is proportionally diminished with a consequent reduction of acetyl-CoA entering the tricarboxylic acid (TCA) cycle. Then, cytosolic pyruvate being towards the formation of lactate which is then expelled from the cell by the upregulation of both lactate dehydrogenase A (LDH-A) and MCT-1. The higher production of lactate through this action favors anabolic production of biomass, and nucleotide synthesis [94]. However, the oxidative phosphorylation stays more efficient in terms of ATP production than aerobic glycolysis because of the shunt of the TCA cycle. PDK transcription is also regulated by insulin, glucocorticoids, thyroid hormone and fatty acids [95] which allow the metabolic flexibility [94].

\section{Warburg effect activation through canonical WNT/ $\beta$-catenin pathway stimulation (Fig. 1)}

Several studies have shown that aerobic glycolysis is induced by overactivation of the $\mathrm{WNT} / \beta$-catenin pathway through a direct activation of PDK1 and MCT-1 [31, 35, 96, 97]. $\beta$-catenin activation induces the expression of PI3K/Akt signaling [56, 57].

Increase rate of glucose metabolism is associated with the overactivation of PI3K/Akt pathway [98]. Activation of PI3K/Akt pathway stimulates HIF-1 $\alpha$ (hypoxia-inducible factor 1- $\alpha$ ) [99], which induces stimulation of glycolytic enzymes such as Glut, LDH-A, PDK1 and PKM2 [99, 100].

Glut-1 and Glut-3 are mainly important for the insulin-sensitive homeostasis of glucose transport [101]. Then, the conversion of phosphoenolpyruvate (PEP) and ADP into pyruvate is the final step in glycolysis after glucose entered the cell. The enzyme pyruvate kinase (PK) catalyzes this reaction. PK have four isoforms: PKM1, PKM2, PKL, and PKR. The dimeric form of PKM2 has low affinity with PEP [102]. Under high glucose concentration, PKM2 is translocated to the nucleus through the action of peptidyl-prolyl isomerase 1 (Pin1) [103], which reduces its activity and targets PKM2 toward lysosome-dependent degradation [104]. Nuclear PKM2 binds nuclear $\beta$-catenin and then induces c-Mycmediated expression of glycolytic enzymes including Glut, LDH-A, PDK1, and PKM2 [105].

Activated c-Myc also activates glutaminolysis and tends to nucleotide synthesis [106] by activating HIF- $1 \alpha$ which controls PDK1 [107]. A minor part of the pyruvate is converted into acetyl-CoA which enters the TCA cycle and become citrate for promoting protein and lipid synthesis.

\section{Lactate production in ASD}

Up to now, few studies have described the expression of the different glycolytic enzymes in ASD. However, several studies have shown elevated lactate levels in ASD patients $[14,18-21,108-110]$. In the same way, production of pyruvate is stimulated $[20,110]$ but with an increased ratio lactate-to-pyruvate $[19,20]$. A recent study has observed a significant increase in LDH-A expression and pyruvate levels in ASD [18]. A recent study have shown a decrease level of $\mathrm{pH}$ associated with the overproduction of lactate in ASD [111]. These findings may suggest an elevation of glycolysis through the phenomenon of aerobic glycolysis in ASD since the dysregulation of this balance has been proposed as a candidate cause of ASD [112]. 


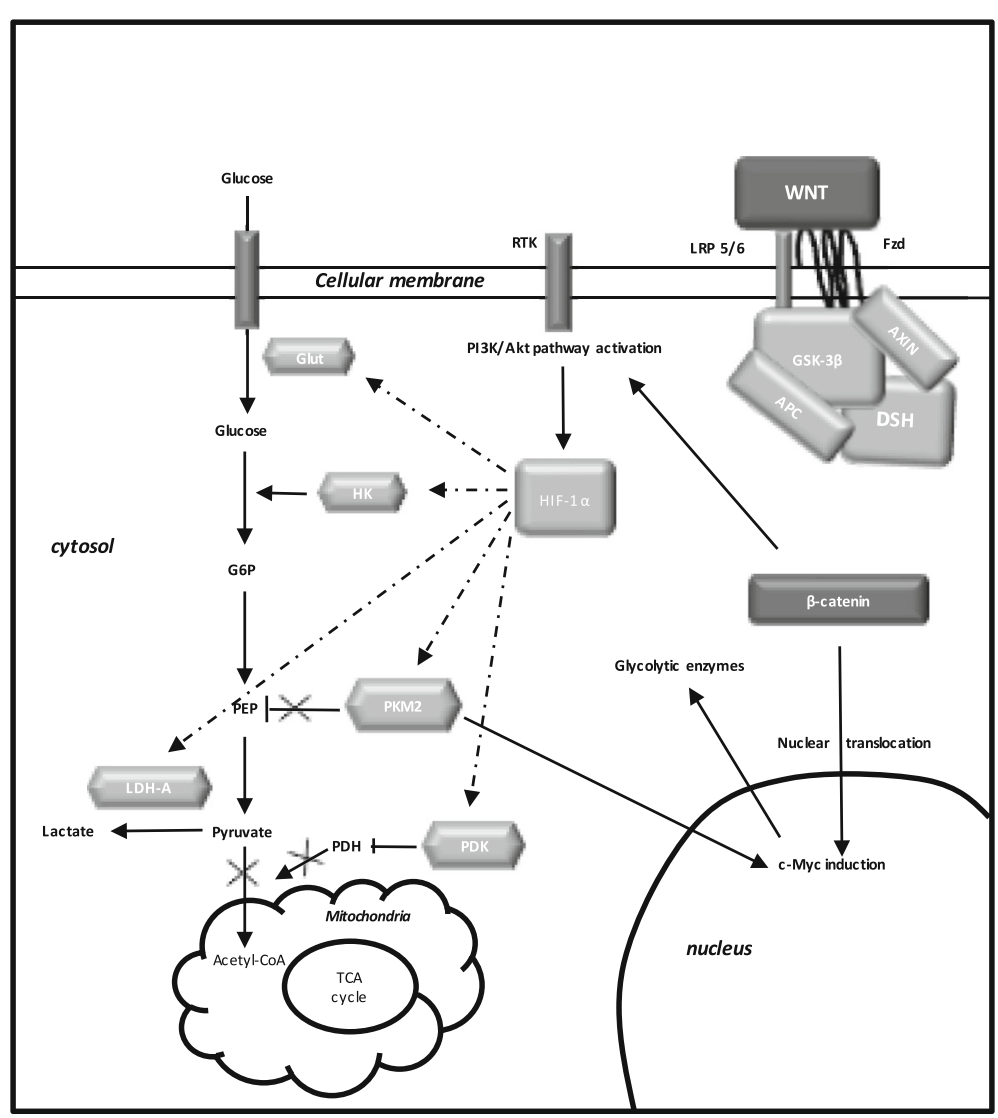

Fig. 1 Relation between activated WNT/ $\beta$-catenin pathway and Warburg effect in ASD. Mutations in ASD lead to activate the presence of WNT ligands. Then, WNT binds both Frizzled and LRP 5/6 receptors to phosphorylate the AXIN/APC/GSK-3 $\beta$ complex. Thus, $\beta$-catenin phosphorylation is stopped and this inhibits its degradation into the proteasome. $\beta$-catenin accumulates in the cytosol and translocates to the nucleus to bind the complex TCF/LEF co transcription factors. WNT target gene transcription is activated by nuclear $\beta$-catenin (PDK, c-Myc, cyclin D1, MCT-1). Glucose also activates the WNT signaling. MCT-1 favors lactate expulsion out of the cell. WNT/ $\beta$-catenin pathway activates tyrosine kinase receptors (TKRs) activity. Activated PI3K/Akt pathway stimulates glucose metabolism. Akt-transformed cells protect against reactive oxygen species stress (ROS) by inducing HIF-1a, which suppresses glucose entry into the TCA cycle. Stimulation of HIF-1a activity activates the expression of the glycolytic enzymes (GLUT, HK, PKM2, LDH-A). Aerobic glycolysis is observed with the increase of lactate production and the decrease of mitochondrial respiration. HIF-1a induced PDK phosphorylates PDH, which resulting in cytosolic pyruvate being shunted into lactate by inducing LDH-A activation. PDK inhibits the PDH complex into the mitochondria, thus pyruvate cannot be fully converted into acetyl-CoA and enter the TCA cycle. c-Myc and cyclin D1 also stimulates LDH-A activity which converts cytosolic pyruvate into lactate. Activated PKM2 translocates to the nucleus to bind $\beta$-catenin and then to induce the expression of c-Myc

The canonical WNT/ $\beta$-catenin pathway is upregulated in ASD, and is one of the major pathways involved in developmental cognitive disorders. In the present review, we examine accumulating evidence of the reprogramming of cellular energy metabolism induced by overexpressed canonical WNT/ $\beta$-catenin pathway for a shift in energy production from mitochondrial oxidative phosphorylation to aerobic glycolysis as the alternative of ATP despite the availability of oxygen; a phenomenon called Warburg effect. Over-activation of the $\mathrm{WNT} / \beta$ catenin pathway induces the transduction of $\mathrm{WNT} / \beta$-catenin target genes, c-Myc and cyclin D1, and activates PI3K/Akt pathway, leading to HIF-1 $\alpha$ stabilization. Both transcription of WNT-responsive genes and HIF- $1 \alpha$ stabilization induce the transactivation of genes encoding aerobic glycolysis enzymes c-Myc, PDK, LDH-A, and MCT-1, which might explain the decreased glucose entry into the TCA cycle in mitochondria, and the conversion of a large part of glucose into lactate in cytosol, observed in the ASD. Dysregulation of cellular energy metabolism induced by over-expressed canonical WNT/ $\beta$-catenin pathway might promote dysregulation and progression of the core neurodevelopmental pathways associated with the clinical presentation of ASD. Warburg effect regulation might be an innovative mechanism for therapeutic development in ASD, through the canonical $\mathrm{WNT} / \beta$-catenin pathway as potential therapeutic target. 


\section{Abbreviations}

Acetyl-coA: Acetyl-coenzyme A; APC: Adenomatous polyposis coli; ASD: Autism spectrum disorders; CNS: Central nervous system; DSH: Disheveled; FZD: Frizzled; GLUT: Glucose transporter; GSK-3B: Glycogen synthase kinase-3 $\beta$; HIF-1a: Hypoxia induce factor 1 alpha; LDH: Lactate dehydrogenase; LRP 5/6: Low-density lipoprotein receptor-related protein 5/6; MCT-1: Monocarboxylate lactate transporter-1; PDH: Pyruvate dehydrogenase complex; PDK: Pyruvate dehydrogenase kinase; PI3KAkt: Phosphatidylinositol 3-kinase-protein kinase B; PK: Pyruvate kinase; ROS: Reactive oxygen species; TCA: Tricarboxylic acid; TCF/LEF: T-cell factor/lymphoid enhancer factor; VPA: Valproic acid

\section{Acknowledgements}

Not applicable.

\section{Funding}

No funding.

\section{Availability of data and materials}

Data sharing not applicable to this article as no datasets were generated or analyzed during the current study.

\section{Authors' contributions}

Both authors listed, have made substantial, direct and intellectual contribution to the work. Both authors read and approved the final manuscript.

\section{Ethics approval and consent to participate}

Not applicable.

\section{Consent for publication}

Not applicable.

\section{Competing interests}

The authors declare that they have no competing interests.

\section{Publisher's Note}

Springer Nature remains neutral with regard to jurisdictional claims in published maps and institutional affiliations.

\section{Author details}

'Laboratoire de Mathématiques et Applications (LMA), UMR CNRS 7348, CHU Poitiers, University of Poitiers, Poitiers, France. ' Laboratoire de Mathématiques et Applications (LMA), UMR CNRS 7348, University of Poitiers, 11 Boulevard Marie et Pierre Curie, Poitiers, France. ${ }^{3} \mathrm{CHU}$ Amiens Picardie, Université Picardie Jules Verne (UPJV), Amiens, France.

\section{Received: 18 October 2017 Accepted: 13 December 2017}

\section{Published online: 04 January 2018}

\section{References}

1. Posar A, Resca F, Visconti P. Autism according to diagnostic and statistical manual of mental disorders 5 (th) edition: the need for further improvements. J Pediatr Neurosci. 2015;10:146-8.

2. Esposito G, Venuti P. Analysis of toddlers' gait after six months of independent walking to identify autism: a preliminary study. Percept Mot Skills. 2008;106:259-69.

3. Esposito G, Venuti P, Maestro S, Muratori F. An exploration of symmetry in early autism spectrum disorders: analysis of lying. Brain and Development. 2009;31:131-8.

4. Ospina MB, Krebs Seida J, Clark B, Karkhaneh M, Hartling L, Tjosvold L, et al. Behavioural and developmental interventions for autism spectrum disorder: a clinical systematic review. PLoS One. 2008;3:e3755.

5. Altemeier WA, Altemeier LE. How can early, intensive training help a genetic disorder? Pediatr Ann. 2009;38:167-70. 172

6. Persico AM, Napolioni V. Autism genetics. Behav Brain Res. 2013;251:95-112.

7. Kwan V, Unda BK, Singh KK. Wnt signaling networks in autism spectrum disorder and intellectual disability. J Neurodev Disord. 2016:8:45.

8. Krumm N, O'Roak BJ, Shendure J, Eichler EEA. De novo convergence of autism genetics and molecular neuroscience. Trends Neurosci. 2014;37:95-105.
9. Caracci MO, Ávila ME, De Ferrari GV. Synaptic Wnt/GSK3 $\beta$ signaling hub in autism. Neural Plast 2016;2016:9603751.

10. Mulligan KA, Cheyette BNR. Neurodevelopmental perspectives on Wnt signaling in psychiatry. Mol. Neuropsychiatry. 2017;2:219-46.

11. Pate KT, Stringari C, Sprowl-Tanio S, Wang K, TeSlaa T, Hoverter NP, et al. Wnt signaling directs a metabolic program of glycolysis and angiogenesis in colon cancer. EMBO J. 2014;33:1454-73.

12. Warburg O. On the origin of cancer cells. Science. 1956;123:309-14.

13. Frye RE, Rossignol DA. Mitochondrial dysfunction can connect the diverse medical symptoms associated with autism spectrum disorders. Pediatr Res. 2011;69:41R-7R.

14. Rossignol DA, Frye RE. Mitochondrial dysfunction in autism spectrum disorders: a systematic review and meta-analysis. Mol Psychiatry. 2012;17:290-314.

15. Rossignol DA, Frye REA. Review of research trends in physiological abnormalities in autism spectrum disorders: immune dysregulation, inflammation, oxidative stress, mitochondrial dysfunction and environmental toxicant exposures. Mol Psychiatry. 2012:17:389-401.

16. Goh S, Dong Z, Zhang Y, DiMauro S, Peterson BS. Mitochondrial dysfunction as a neurobiological subtype of autism spectrum disorder: evidence from brain imaging. JAMA Psychiatry. 2014;71:665-71.

17. Hollis F, Kanellopoulos AK, Bagni C. Mitochondrial dysfunction in autism Spectrum disorder: clinical features and perspectives. Curr Opin Neurobiol. 2017:45:178-87.

18. Khemakhem AM, Frye RE, El-Ansary A, Al-Ayadhi L, Bacha AB. Novel biomarkers of metabolic dysfunction is autism spectrum disorder: potential for biological diagnostic markers. Metab Brain Dis. 2017.

19. Correia C, Coutinho AM, Diogo L, Grazina M, Marques C, Miquel T, et al. Brief report: high frequency of biochemical markers for mitochondrial dysfunction in autism: no association with the mitochondrial aspartate/ glutamate carrier SLC25A12 gene. J Autism Dev Disord. 2006;36:1137-40.

20. László A, Horváth E, Eck E, Fekete M. Serum serotonin, lactate and pyruvate levels in infantile autistic children. Clin. Chim. Acta Int. J Clin Chem. 1994;229:205-7

21. Weissman JR, Kelley Rl, Bauman ML, Cohen BH, Murray KF, Mitchell RL, et al. Mitochondrial disease in autism spectrum disorder patients: a cohort analysis. PLoS One. 2008:3:e3815.

22. van Amerongen $R$, Nusse $R$. Towards an integrated view of Wnt signaling in development. Dev. Camb. Engl. 2009:136:3205-14.

23. Al-Harthi L. Wnt/ $\beta$-catenin and its diverse physiological cell signaling pathways in neurodegenerative and neuropsychiatric disorders. J Neurolmmune Pharmacol. 2012;7:725-30.

24. Ahmad-Annuar A, Ciani L, Simeonidis I, Herreros J, Fredj NB, Rosso SB, et al. Signaling across the synapse: a role for Wnt and Dishevelled in presynaptic assembly and neurotransmitter release. J Cell Biol. 2006;174:127-39.

25. Inestrosa NC, Arenas E. Emerging roles of Wnts in the adult nervous system. Nat Rev Neurosci. 2010;11:77-86.

26. Itasaki N, Jones CM, Mercurio S, Rowe A, Domingos PM, Smith JC, et al. Wise, a context-dependent activator and inhibitor of Wnt signalling. Dev Camb Engl. 2003:130:4295-305.

27. Caricasole A, Ferraro T, lacovelli L, Barletta E, Caruso A, Melchiorri D, et al. Functional characterization of WNT7A signaling in $\mathrm{PC} 12$ cells: interaction with a FZD5 x LRP6 receptor complex and modulation by Dickkopf proteins. J Biol Chem. 2003:278:37024-31.

28. Sharma K, Choi S-Y, Zhang Y, Nieland TJF, Long S, Li M, et al. Highthroughput genetic screen for synaptogenic factors: identification of LRP6 as critical for excitatory synapse development. Cell Rep. 2013;5:1330-41.

29. Lecarpentier Y, Claes V, Duthoit G, Hébert J-L. Circadian rhythms, Wnt/betacatenin pathway and PPAR alpha/gamma profiles in diseases with primary or secondary cardiac dysfunction. Front Physiol. 2014:5:429.

30. Vallée A, Lecarpentier Y, Guillevin R, Vallée J-N. Thermodynamics in gliomas: interactions between the canonical WNT/Beta-catenin pathway and PPAR gamma. Front Physiol. 2017:8:352

31. Vallée $A$, Guillevin $R$, Vallée J.-N. Vasculogenesis and angiogenesis initiation under normoxic conditions through Wnt/B-catenin pathway in gliomas. Rev Neurosci. 2018;29(1):71-91

32. Lecarpentier Y, Claes V, Vallée A, Hébert J-L. Interactions between PPAR gamma and the canonical Wnt/Beta-catenin pathway in type 2 diabetes and colon cancer. PPAR Res. 2017:2017:1-9.

33. Vallée A, Lecarpentier $Y$. Alzheimer disease: crosstalk between the canonical Wnt/Beta-catenin pathway and PPARs alpha and gamma. Front Neurosci. 2016;10:459. 
34. Vallée A, Lecarpentier Y, Guillevin R, Vallée J-N. Effects of Cannabidiol interactions with Wnt/ $\beta$-catenin pathway and PPARy on oxidative stress and neuroinflammation in Alzheimer's disease. Acta Biochim Biophys Sin. 2017:1-14.

35. Vallée A, Lecarpentier Y, Guillevin R, Vallée J-N. Aerobic glycolysis hypothesis through WNT/Beta-catenin pathway in exudative age-related macular degeneration. J Mol Neurosci MN. 2017;62:368-79.

36. Vallée A, Lecarpentier Y, Guillevin R, Vallée J-N. PPARy agonists: potential treatments for exudative age-related macular degeneration. Life Sci. 2017; 188:123-30.

37. Lecarpentier $Y$, Vallée A. Opposite interplay between PPAR gamma and canonical Wnt/Beta-catenin pathway in amyotrophic lateral sclerosis. Front Neurol. 2016;7:100.

38. Vallée A, Vallée J-N, Guillevin R, Lecarpentier Y. Interactions between the canonical WNT/Beta-catenin pathway and PPAR gamma on Neuroinflammation, demyelination, and Remyelination in multiple sclerosis. Cell Mol Neurobiol. 2017. https://doi.org/10.1007/s10571-017-0550-9.

39. Marchetti B, Pluchino S. Wnt your brain be inflamed? Yes, it Wnt. Trends Mol Med. 2013;19:144-56.

40. Logan CY, Nusse R. The Wnt signaling pathway in development and disease. Annu Rev Cell Dev Biol. 2004;20:781-810.

41. Angers S, Moon RT. Proximal events in Wnt signal transduction. Nat Rev Mol Cell Biol. 2009;10(7):468-77.

42. Clevers $H$, Nusse R. Wnt/ $\beta$-catenin signaling and disease. Cell. 2012;149:1192-205.

43. Aberle H, Bauer A, Stappert J, Kispert A, Kemler R. $\beta$-catenin is a target for the ubiquitin-proteasome pathway. EMBO J. 1997;16:3797-804

44. Brazil DP, Yang Z-Z, Hemmings BA. Advances in protein kinase B signalling: AKTion on multiple fronts. Trends Biochem Sci. 2004;29:233-42.

45. Ciuffreda L, Di Sanza C, Incani UC, Milella M. The mTOR pathway: a new target in cancer therapy. Curr Cancer Drug Targets. 2010;10:484-95.

46. Heras-Sandoval D, Pérez-Rojas JM, Hernández-Damián J, Pedraza-Chaverri J. The role of PI3K/AKT/mTOR pathway in the modulation of autophagy and the clearance of protein aggregates in neurodegeneration. Cell Signal. 2014;26:2694-701.

47. Yu JSL, Cui W. Proliferation, survival and metabolism: the role of PI3K/AKT/ mTOR signalling in pluripotency and cell fate determination. Dev. Camb. Engl. 2016;143:3050-60.

48. Huang J, Nguyen-McCarty M, Hexner EO, Danet-Desnoyers G, Klein PS Maintenance of hematopoietic stem cells through regulation of Wnt and mTOR pathways. Nat Med. 2012;18:1778-85.

49. Chen J, Alberts I, Li X. Dysregulation of the IGF-I/PI3K/AKT/mTOR signaling pathway in autism spectrum disorders. Int. J. Dev. Neurosci. Off. J. Int. Soc Dev Neurosci. 2014;35:35-41.

50. Zhou B, Buckley ST, Patel V, Liu Y, Luo J, Krishnaveni MS, et al. Troglitazone attenuates TGF- $\beta 1$-induced EMT in alveolar epithelial cells via a PPARYindependent mechanism. PLoS One. 2012;7:e38827.

51. Ambacher KK, Pitzul KB, Karajgikar M, Hamilton A, Ferguson SS, Cregan SP. The JNK- and AKT/GSK3 $\beta$ - signaling pathways converge to regulate puma induction and neuronal apoptosis induced by trophic factor deprivation. Hetman M, editor. PLoS One 2012;7:e46885.

52. Hur E-M, Zhou F-Q. GSK3 signalling in neural development. Nat Rev Neurosci. 2010;11:539-51.

53. Wu D, Pan W. GSK3: a multifaceted kinase in Wnt signaling. Trends Biochem Sci. 2010;35:161-8.

54. Ross SE, Erickson RL, Hemati N, MacDougald OA. Glycogen synthase kinase 3 is an insulin-regulated C/EBPalpha kinase. Mol Cell Biol. 1999;19:8433-41.

55. Tang Q-Q, Grønborg M, Huang H, Kim J-W, Otto TC, Pandey A, et al. Sequential phosphorylation of CCAAT enhancer-binding protein beta by MAPK and glycogen synthase kinase 3 beta is required for adipogenesis. Proc Natl Acad Sci U S A. 2005;102:9766-71.

56. Park KS, Lee RD, Kang S-K, Han SY, Park KL, Yang KH, et al. Neuronal differentiation of embryonic midbrain cells by upregulation of peroxisome proliferator-activated receptor-gamma via the JNK-dependent pathway. Exp Cell Res. 2004;297:424-33.

57. Yue $X$, Lan F, Yang W, Yang Y, Han L, Zhang A, et al. Interruption of $\beta$ catenin suppresses the EGFR pathway by blocking multiple oncogenic targets in human glioma cells. Brain Res. 2010;1366:27-37.

58. De Ferrari GV, Moon RT. The ups and downs of Wnt signaling in prevalent neurological disorders. Oncogene. 2006;25:7545-53.
59. Okerlund ND, Cheyette BNR. Synaptic Wnt signaling-a contributor to major psychiatric disorders? J Neurodev Disord. 2011;3:162-74.

60. Kalkman HOA. Review of the evidence for the canonical Wnt pathway in autism spectrum disorders. Mol. Autism. 2012:3:10.

61. Wassink TH, Piven J, Vieland VJ, Huang J, Swiderski RE, Pietila J, et al. Evidence supporting WNT2 as an autism susceptibility gene. Am J Med Genet. 2001;105:406-13.

62. Boon EMJ, van der Neut R, van de Wetering M, Clevers H, Pals ST. Wnt signaling regulates expression of the receptor tyrosine kinase met in colorectal cancer. Cancer Res. 2002;62:5126-8.

63. Tuynman JB, Vermeulen L, Boon EM, Kemper $K$, Zwinderman AH, Peppelenbosch MP, et al. Cyclooxygenase-2 inhibition inhibits c-met kinase activity and Wnt activity in colon cancer. Cancer Res. 2008;68:1213-20.

64. Thompson BA, Tremblay V, Lin G. Bochar DA. CHD8 is an ATP-dependent chromatin remodeling factor that regulates beta-catenin target genes. Mol Cell Biol. 2008;28:3894-904

65. O'Roak BJ, Deriziotis P, Lee C, Vives L, Schwartz JJ, Girirajan S, et al. Exome sequencing in sporadic autism spectrum disorders identifies severe de novo mutations. Nat Genet. 2011:43:585-9.

66. Hong JY, Park J-I, Lee M, Muñoz WA, Miller RK, Ji H, et al. Down's-syndromerelated kinase Dyrk1A modulates the p120-catenin-kaiso trajectory of the Wnt signaling pathway. J Cell Sci. 2012;125:561-9.

67. Martin P-M, Yang X, Robin N, Lam E, Rabinowitz JS, Erdman CA, et al. A rare WNT1 missense variant overrepresented in ASD leads to increased WNT signal pathway activation. Transl Psychiatry. 2013;3:e301.

68. Gilman SR, lossifov I, Levy D, Ronemus M, Wigler M, Vitkup D. Rare de novo variants associated with autism implicate a large functional network of genes involved in formation and function of synapses. Neuron. 2011;70:898-907.

69. Turner TN, Hormozdiari F, Duyzend MH, McClymont SA, Hook PW, lossifov I, et al. Genome sequencing of autism-affected families reveals disruption of putative noncoding regulatory DNA. Am J Hum Genet. 2016;98:58-74.

70. Barber JC, Ellis KH, Bowles LV, Delhanty JD, Ede RF, Male BM, et al. Adenomatous polyposis coli and a cytogenetic deletion of chromosome 5 resulting from a maternal intrachromosomal insertion. J Med Genet. 1994;31:312-6.

71. Zhou X-L, Giacobini M, Anderlid B-M, Anckarsäter H, Omrani D, Gillberg C, et al. Association of adenomatous polyposis coli (APC) gene polymorphisms with autism spectrum disorder (ASD). Am. J. Med. Genet. Part B Neuropsychiatr. Genet. Off. Publ. Int. Soc Psychiatr Genet. 2007;144B:351-4.

72. Mohn JL, Alexander J, Pirone A, Palka CD, Lee S-Y, Mebane L, et al. Adenomatous polyposis coli protein deletion leads to cognitive and autism-like disabilities. Mol Psychiatry. 2014;19:1133-42

73. O'Roak BJ, Vives L, Girirajan S, Karakoc E, Krumm N, Coe BP, et al. Sporadic autism exomes reveal a highly interconnected protein network of de novo mutations. Nature. 2012;485:246-50.

74. Talkowski ME, Rosenfeld JA, Blumenthal I, Pillalamarri V, Chiang C, Heilbut A et al. Sequencing chromosomal abnormalities reveals neurodevelopmental loci that confer risk across diagnostic boundaries. Cell. 2012:149:525-37.

75. Lotan A, Fenckova M, Bralten J, Alttoa A, Dixson L, Williams RW, et al. Neuroinformatic analyses of common and distinct genetic components associated with major neuropsychiatric disorders. Front Neurosci. 2014;8:331.

76. Iossifov I, O'Roak BJ, Sanders SJ, Ronemus M, Krumm N, Levy D, et al. The contribution of de novo coding mutations to autism spectrum disorder. Nature. 2014:515:216-21.

77. McBride KL, Varga EA, Pastore MT, Prior TW, Manickam K, Atkin JF, et al. Confirmation study of PTEN mutations among individuals with autism or developmental delays/mental retardation and macrocephaly. Autism res. Off. J. Int. Soc Autism Res. 2010:3:137-41.

78. O'Roak BJ, Vives L, Fu W, Egertson JD, Stanaway IB, Phelps IG, et al. Multiplex targeted sequencing identifies recurrently mutated genes in autism spectrum disorders. Science. 2012;338:1619-22.

79. Spinelli L, Black FM, Berg JN, Eickholt BJ, Leslie NR. Functionally distinct groups of inherited PTEN mutations in autism and tumour syndromes. J Med Genet. 2015:52:128-34.

80. Frazier TW, Embacher R, Tilot AK, Koenig K, Mester J, Eng C. Molecular and phenotypic abnormalities in individuals with germline heterozygous PTEN mutations and autism. Mol Psychiatry. 2015;20:1132-8.

81. Vanhaesebroeck B, Stephens L, Hawkins P. PI3K signalling: the path to discovery and understanding. Nat Rev Mol Cell Biol. 2012;13:195-203. 
82. Mao H, Lebrun DG, Yang J, Zhu VF, Li M. Deregulated signaling pathways in glioblastoma multiforme: molecular mechanisms and therapeutic targets. Cancer Investig. 2012;30:48-56.

83. Kwon C-H, Luikart BW, Powell CM, Zhou J, Matheny SA, Zhang W, et al. Pten regulates neuronal arborization and social interaction in mice. Neuron. 2006:50:377-88

84. Lugo JN, Smith GD, Arbuckle EP, White J, Holley AJ, Floruta CM, et al. Deletion of PTEN produces autism-like behavioral deficits and alterations in synaptic proteins. Front Mol Neurosci. 2014;7:27.

85. Chen Y, Huang W-C, Séjourné J, Clipperton-Allen AE, Page DT. Pten mutations Alter brain growth trajectory and allocation of cell types through elevated $\beta$-catenin signaling. J Neurosci. 2015;35:10252-67.

86. Meunier H, Carraz G, Neunier Y, Eymard P, Aimard M. Pharmacodynamic properties of N-dipropylacetic acid. Therapie. 1963;18:435-8.

87. Peterson GM, Naunton M. Valproate: a simple chemical with so much to offer. J Clin Pharm Ther. 2005;30:417-21

88. Phiel CJ, Zhang F, Huang EY, Guenther MG, Lazar MA, Klein PS. Histone deacetylase is a direct target of valproic acid, a potent anticonvulsant, mood stabilizer, and teratogen. J Biol Chem. 2001;276:36734-41.

89. Go HS, Kim KC, Choi CS, Jeon SJ, Kwon KJ, Han S-H, et al. Prenatal exposure to valproic acid increases the neural progenitor cell pool and induces macrocephaly in rat brain via a mechanism involving the GSK-3 $\beta / \beta$-catenin pathway. Neuropharmacology. 2012;63:1028-41.

90. Wang L, Liu Y, Li S, Long Z-Y, Wnt WY-M. Signaling pathway participates in valproic acid-induced neuronal differentiation of neural stem cells. Int J Clin Exp Pathol. 2015;8:578-85.

91. Qin L, Dai X, Yin Y. Valproic acid exposure sequentially activates Wnt and mTOR pathways in rats. Mol Cell Neurosci. 2016;75:27-35.

92. Christensen J, Grønborg TK, Sørensen MJ, Schendel D, Parner ET, Pedersen $\mathrm{LH}$, et al. Prenatal valproate exposure and risk of autism spectrum disorders and childhood autism. JAMA. 2013;309:1696-703.

93. Roche TE, Baker JC, Yan X, Hiromasa Y, Gong X, Peng T, et al. Distinct regulatory properties of pyruvate dehydrogenase kinase and phosphatase isoforms. Prog Nucleic Acid Res Mol Biol. 2001;70:33-75.

94. Zhang S, Hulver MW, McMillan RP, Cline MA, Gilbert ER. The pivotal role of pyruvate dehydrogenase kinases in metabolic flexibility. Nutr Metab. 2014;11:10.

95. Lee I-K. The role of pyruvate dehydrogenase kinase in diabetes and obesity. Diabetes Metab J. 2014;38:181-6.

96. Thompson CB. Wht meets Warburg: another piece in the puzzle? EMBO J. 2014;33:1420-2

97. Lecarpentier Y, Claes V, Vallée A, Hébert J-L. Thermodynamics in cancers: opposing interactions between PPAR gamma and the canonical WNT/betacatenin pathway. Clin Transl Med. 2017;6:14.

98. Reuter S, Gupta SC, Chaturvedi MM, Aggarwal BB. Oxidative stress, inflammation, and cancer: how are they linked? Free Radic Biol Med. 2010:49:1603-16.

99. Sun $\mathrm{Q}$, Chen $\mathrm{X}, \mathrm{Ma}$ J, Peng H, Wang F, Zha X, et al. Mammalian target of rapamycin up-regulation of pyruvate kinase isoenzyme type $M 2$ is critical for aerobic glycolysis and tumor growth. Proc Natl Acad Sci U S A. 2011;108:4129-34.

100. Semenza GL. HIF-1: upstream and downstream of cancer metabolism. Curr Opin Genet Dev. 2010;20:51-6.

101. McEwen BS, Reagan LP. Glucose transporter expression in the central nervous system: relationship to synaptic function. Eur J Pharmacol. 2004:490: 13-24.

102. Christofk HR, Vander Heiden MG, Harris MH, Ramanathan A, Gerszten RE, Wei $R$, et al. The M2 splice isoform of pyruvate kinase is important for cancer metabolism and tumour growth. Nature. 2008;452:230-3.

103. Harris RA, Tindale L, Cumming RC. Age-dependent metabolic dysregulation in cancer and Alzheimer's disease. Biogerontology. 2014;15:559-77.

104. Lv L, Li D, Zhao D, Lin R, Chu Y, Zhang H, et al. Acetylation targets the M2 isoform of pyruvate kinase for degradation through chaperone-mediated autophagy and promotes tumor growth. Mol Cell. 2011;42:719-30.

105. Yang W, Xia Y, Hawke D, Li X, Liang J, Xing D, et al. PKM2 phosphorylates histone $\mathrm{H} 3$ and promotes gene transcription and tumorigenesis. Cell. 2012;150:685-96.

106. Wise DR, DeBerardinis RJ, Mancuso A, Sayed N, Zhang X-Y, Pfeiffer HK, et al. Myc regulates a transcriptional program that stimulates mitochondrial glutaminolysis and leads to glutamine addiction. Proc Natl Acad Sci U S A 2008;105:18782-7.
107. Kim J, Gao P, Liu Y-C, Semenza GL, Dang CV. Hypoxia-inducible factor 1 and dysregulated c-Myc cooperatively induce vascular endothelial growth factor and metabolic switches hexokinase 2 and pyruvate dehydrogenase kinase 1. Mol Cell Biol. 2007;27:7381-93.

108. Moreno H, Borjas L, Arrieta A, Sáez L, Prassad A, Estévez J, et al. Clinical heterogeneity of the autistic syndrome: a study of 60 families. Investig Clin. 1992;33:13-31.

109. Oliveira G, Diogo L, Grazina M, Garcia P, Ataíde A, Marques C, et al. Mitochondrial dysfunction in autism spectrum disorders: a population-based study. Dev Med Child Neurol. 2005;47:185-9.

110. Germanò E, Gagliano A, Magazù A, Calarese T, Calabrò ME, Bonsignore M, et al. Neurobiology of autism: study of a sample of autistic children. Minerva Pediatr. 2006;58:109-20.

111. Hagihara H, Catts VS, Katayama Y, Shoji H, Takagi T, Huang FL, et al. Decreased brain $\mathrm{pH}$ as a shared Endophenotype of psychiatric disorders. Neuropsychopharmacol. Off. Publ. Am. Coll. Neuropsychopharmacol. 2017. https://doi.org/10.1038/npp.2017.167

112. Marín O. Interneuron dysfunction in psychiatric disorders. Nat Rev Neurosci. 2012:13:107-20.

113. Naito AT, Shiojima I, Komuro I. Wnt signaling and aging-related heart disorders. Circ Res. 2010;107:1295-303.

114. Wang X, Xiao Y, Mou Y, Zhao Y, Blankesteijn WM, Hall JLA. Role for the beta-catenin/T-cell factor signaling cascade in vascular remodeling. Circ Res. 2002:90:340-7.

115. Morin PJ, Sparks AB, Korinek V, Barker N, Clevers H, Vogelstein B, et al. Activation of beta-catenin-Tcf signaling in colon cancer by mutations in beta-catenin or APC. Science. 1997;275:1787-90.

116. Lecarpentier Y, Schussler O, Claes V, Vallée A. The Myofibroblast: TGFß-1, a conductor which plays a key role in fibrosis by regulating the balance between PPARy and the canonical WNT pathway. Nuclear Receptor Research. 2017:4:23.

117. Vallée A, Lecarpentier $Y$, Vallée J-N. Thermodynamic aspects and reprogramming cellular energy metabolism during the fibrosis process. Int J Mol Sci. 2017;18.

118. Godin JD, Poizat G, Hickey MA, Maschat F, Humbert S. Mutant huntingtinimpaired degradation of beta-catenin causes neurotoxicity in Huntington's disease. EMBO J. 2010:29:2433-45.

119. Vallée A, Lecarpentier $Y$, Guillevin R, Vallée J-N. Interactions between TGF- $\beta 1$, canonical WNT/ $\beta$-catenin pathway and PPAR $\gamma$ in radiation-induced fibrosis. Oncotarget. 2017;8:90579-604

120. Vallée A, Lecarpentier Y, Guillevin R, Vallée J-N. Reprogramming energetic metabolism in Alzheimer's disease. Life Sci. 2017. https://doi.org/10.1016/j.lfs. 2017.10.033.

121. Garcia-Gras E, Lombardi R, Giocondo MJ, Willerson JT, Schneider MD, Khoury DS, et al. Suppression of canonical Wnt/beta-catenin signaling by nuclear plakoglobin recapitulates phenotype of arrhythmogenic right ventricular cardiomyopathy. J Clin Invest. 2006;116:2012-21.

122. Valvezan AJ, Klein PS. GSK-3 and Wnt signaling in neurogenesis and bipolar disorder. Front Mol Neurosci. 2012;5:1.

123. Canalis E. Wht signalling in osteoporosis: mechanisms and novel therapeutic approaches. Nat Rev Endocrinol. 2013;9:575-83.

124. Berwick DC, Harvey K. The importance of Wnt signalling for neurodegeneration in Parkinson's disease. Biochem Soc Trans. 2012;40:1123-8. 